\title{
Safety of Blood Maintained in Zimbabwe: Low Transfusion Transmissible Infections among Blood Donors
}

\author{
David Zezai ${ }^{*}$, Palanivel Chinnakali², Riitta A. Dlodlo3 ${ }^{3}$, Hamufare D. Mugauri ${ }^{4}$, Philip Owiti ${ }^{3,5}$, \\ Menard Mutenherwa' ${ }^{1}$, George Mavunganidze' ${ }^{1}$, Lucy M. Marowa ${ }^{1}$, Tonderai Mapako ${ }^{1}$ \\ ${ }^{1}$ National Blood Service Zimbabwe (NBSZ), Harare, Zimbabwe \\ ${ }^{2}$ Department of Preventive and Social Medicine, Jawaharlal Institute of Postgraduate Medical Education \& Research (JIPMER), \\ Puducherry, India \\ ${ }^{3}$ International Union against Tuberculosis and Lung Disease, Paris, France \\ ${ }^{4}$ Ministry of Health and Child Care, AIDS and TB Unit, Harare, Zimbabwe \\ ${ }^{5}$ National Tuberculosis, Leprosy and Lung Disease Programme, Ministry of Health, Nairobi, Kenya \\ Email:*dzezai@gmail.com
}

How to cite this paper: Zezai, D., Chinnakali, P., Dlodlo, R.A., Mugauri, H.D., Owiti, P., Mutenherwa, M., Mavunganidze, G., Marowa, L.M. and Mapako, T. (2020) Safety of Blood Maintained in Zimbabwe: Low Transfusion Transmissible Infections among Blood Donors. Journal of Biosciences and Medicines, 8, 35-43. https://doi.org/10.4236/jbm.2020.87004

Received: April 27, 2020

Accepted: July 18, 2020

Published: July 21, 2020

Copyright $\odot 2020$ by author(s) and Scientific Research Publishing Inc. This work is licensed under the Creative Commons Attribution International License (CC BY 4.0).

http://creativecommons.org/licenses/by/4.0/ (c) (i) Open Access

\begin{abstract}
Background: Low level of transfusion transmissible infections (TTIs) is an indicator of a well-performing blood donor program. Aim: The study was designed to estimate the prevalence of TTIs and to evaluate the demographic characteristics of reactive and non-reactive blood donors in Zimbabwe in 2018. Methods: A cross-sectional study was conducted using routinely available data from January to December 2018 in five branches of National Blood Service Zimbabwe (NBSZ). After initial screening for high-risk behavior with a questionnaire, weight, blood pressure and hemoglobin level, eligible donors were invited for blood donation. The following laboratory tests for TTIs were done: antibodies and antigen tests for human immunodeficiency virus 1 and 2 (HIV 1/2), tests for the surface antigen of hepatitis B virus (HBV), testing for hepatitis $\mathrm{C}$ virus (HCV) antibody and antibodies for treponema pallidum. Information on age, gender, NBSZ branch, marital status, occupation, donor type (first time/repeat) and TTIs test results were extracted from the NBSZ electronic database (e-Delphyn blood bank software). Results: Out of a sample of 1586 blood donors, thirteen $(0.81 \%)$ were reactive to at least one TTI marker; five $(0.32 \%)$ were reactive for human immunodeficiency virus, seven $(0.44 \%)$ for hepatitis B and one $(0.06 \%)$ for syphilis. There were no samples with co-infection and hepatitis $\mathrm{C}$ virus markers. The prevalence of TTIs was highest in the $31-45$ years age group (2.3\%) and among first-time blood donors (4.7\%). The prevalence of all TTI was low with the highest prevalence of $0.44 \%$ for the hepatitis B virus. Conclusion: Continued concerted efforts will
\end{abstract}


help to maintain satisfactory blood safety in Zimbabwe.

\section{Keywords}

Transfusion Transmissible Infections, Blood Donors, Hepatitis, Human Immunodeficiency Virus, SORT IT

\section{Introduction}

All blood donations should be screened for transfusion transmissible infections (TTIs) to ensure that blood products meet the set safety standards [1]. The TTIs include human immunodeficiency virus 1 and 2 (HIV-1/2), hepatitis B virus (HBV), hepatitis C virus (HCV), and syphilis antibodies (Treponema pallidum) [2]. All blood units which test positive (reactive) for any of the disease markers are discarded in accordance with bio-safety protocols. Data from low-income countries show that the average prevalence of TTIs was $6.71 \%$ in 2016 [3].

Transfusion of infected blood is the cause of 5\% - 10\% of HIV infection in Sub-Saharan Africa, and $12.5 \%$ of patients who receive blood transfusions are at risk of post-transfusion hepatitis [4]. Blood donation programs face challenges in settings with a high HIV and HBV burden, such as Zimbabwe where it was estimated that $14 \%$ of persons in the reproductive age group are HIV-infected [5] and 10\% adults are carriers of HBV [6].

Since the 1950s, the National Blood Service Zimbabwe (NBSZ) has fulfilled its obligation to provide safe blood and adopted the World Health Organization (WHO) recommendation of $100 \%$ voluntary non-remunerated donations [6]. Prospective donors are assessed using a questionnaire for high risk behavior, weight measurement and hemoglobin level. For the past decade, an average of 1.6\% TTIs prevalence has been recorded among blood donors [4], but there are limited NBSZ published work aimed at 1) describing the demographic profile of blood donors, 2) estimating the prevalence of TTIs (HIV, HBV, HCV, and syphilis) and 3) assessing factors associated with TTIs. Assessment of the prevalence of TTIs among blood donors permits monitoring of the occurrence of the TTIs in individual blood donor sub-populations and consequently, the safety of the collected donations. It also gives an idea of the epidemiology of the TTIs among blood donors and informs decision making and policy formulation in the blood donor program.

\section{Methods}

\subsection{Study Design}

A cross-sectional analytical study using routinely collected data was undertaken.

\subsection{National Blood Service Zimbabwe}

NBSZ, a not-for-profit organization, has five branches that are situated in Ha- 
rare, Bulawayo, Mutare, Gweru, and Masvingo. In the past decade, an annual average of 65,687 whole blood units has been collected annually. NBSZ has a standardised donor enrolment and screening procedure which defers donors with high risk behaviors such as: exchanging money, drugs, goods or favours in return for sex, history of accidental exposure to blood or body fluids in the past six months, having been a victim of sexual abuse and having unprotected sex.

\subsection{Screening of Blood Donors}

After receiving a pre-donation counselling, eligible blood donors' history is assessed for high-risk behaviors using a self-administered questionnaire and medical checks are done on weight, blood pressure and haemoglobin level. Based on the assessment, those with high-risk behaviors followed by haemoglobin of $<12.5 \mathrm{~g} / \mathrm{dl}$ for both males and females, blood pressure outside the acceptable range $(<100 / 60 \mathrm{mmHg}$ and $>180 / 100 \mathrm{mmHg})$ and weight $<50 \mathrm{~kg}$ are deferred from blood donation. Every eligible donor is assigned a unique identification number and the collected blood unit undergoes the following tests for TTI markers: antibodies and antigen tests for HIV-1 and HIV-2 (ARCHITECT HIV $\mathrm{Ag} / \mathrm{Ab}$ Combo, Abbott Laboratories, Wiesbaden, Germany), tests for HBsAg (ARCHITECT HBsAg Qualitative II, Abbott Laboratories, Sligo, Ireland), HCV antibodies (ARCHITECT Anti-HCV, Abbott Laboratories, Wiesbaden, Germany) and antibodies for Treponema Pallidum (Abbott Laboratories, ARCHITECT Syphilis TP, Wiesbaden, Germany). First-time donors with reactive first-and second-line test results, for any of the TTI markers, are deferred from donating blood. Those with non-reactive test results for all four TTIs are invited to return after three months (males) and four months (females). They are encouraged to donate as long as they remain free from all infection markers. At every blood donation, tests for all four TTIs are repeated. After enrolment into the blood donor program, information on date of birth, residential address, contact details, gender, NBSZ branch, marital status, occupation, and TTI test results are entered into the electronic database.

\subsection{Study Population}

Individuals with weight more than $50 \mathrm{kgs}$ and aged between 16 and 65 years in the blood donor program in the five branches of the NBSZ from January to December 2018 were included.

\subsection{Data Variables, and Extraction}

Information on age, gender, NBSZ branch, marital status, occupation, donor type (first time/repeat) and TTI test results were extracted from the NBSZ electronic database into an excel spreadsheet.

\subsection{Sample Size Estimation}

The sample size for this study was calculated using a formula for sample size de- 
termination for cross-sectional studies [7], with a Z-score (normal standard deviation) of 1.96 at $95 \%$ confidence, an average TTIs prevalence among blood donors in developing countries of $1.6 \%$ [6], and an absolute precision of 0.05 . A minimum sample size of 2419 samples was required. However, a final sample size of 1586 was considered for the study due to logistical constraints. A simple random sampling of the blood collection forms was then conducted [8] at the five NBSZ branches to proportionally select the total sample size of 1586 for the study.

\subsection{Data Analysis and Statistics}

Data analysis was done in STATA $13.0^{\mathrm{TM}}$ (Stata Corp LLC, TX, USA). Sociodemographic characteristics of blood donors were summarized as proportions. The prevalence of TTIs was expressed as proportions with 95\% confidence intervals using binomial exact test. Socio-demographic factors associated with TTIs were assessed using chi squared test. Level of significance was set at $5 \%$.

\subsection{Ethics Approval}

The study protocol was approved by NBSZ (NBSZ003/2019), Medical Research Council of Zimbabwe (MRCZ/E/247) and The Union Ethics Advisory Group, in Paris, France, (44/19).

\section{Results}

Of the total 1586 blood donors, 972 (61.3\%) were males and the mean (standard deviation) age was 26.5 (11.6) years. The blood donors were distributed across the NBSZ branches as follows; Harare 685 (43.2\%), Bulawayo 293 (18.5\%), Gweru 222 (14.0\%), Masvingo 201 (13.6\%), and Mutare 185 (12.7\%). Donors in the age group of 16-30 years constituted 1124 (70.9\%) of all donors. The overall socio-demographic characteristics are described in Table 1. Approximately half of the donors were not married; 787 (49.6\%). Overall, 783 (49.4\%) were students and $242(15.4 \%)$ constituted a wide range of various professions. Among the blood donors, 232 (14.6\%) were first-time donors and 1354 (85.4\%) were repeat donors.

The prevalence estimates are shown in Table 2 . Thirteen donors $(0.81 \%)$ had at least one TTI; five $(0.32 \%)$ were reactive for HIV $1 / 2$, seven $(0.44 \%)$ for HBV and one $(0.06 \%)$ for Treponema pallidum antibodies. There were no individuals with a co-infection. There were also no donors reactive for $\mathrm{HCV}$, and therefore, no entry was recorded for HCV seropositive results.

Factors associated with TTIs are described in Table 3. The prevalence of TTIs was higher in 31 - 45 years age-group compared to 16 - 30 years age group $(2.3 \%$ vs $0.53 \% ; \mathrm{p}=0.014)$. First-time donors had a higher TTI prevalence compared to repeat donors $(4.74 \%$ vs $0.15 \%$; $<<0.001)$. The other analyzed variables did not show any statistically significant associations with seropositivity for any of the analyzed TTI markers ( $\mathrm{p}>0.05)$. 
Table 1. Socio-demographic characteristics of blood donors in five blood service branches, Zimbabwe, 2018 ( $\mathrm{N}=1586)$.

\begin{tabular}{|c|c|c|c|}
\hline & Characteristics & Number & Percentage \\
\hline & Total & 1586 & 100 \\
\hline \multirow[t]{2}{*}{ Gender } & Male & 972 & 61.3 \\
\hline & Female & 614 & 38.7 \\
\hline \multirow[t]{5}{*}{ Age groups in years } & $16-30$ & 1124 & 70.9 \\
\hline & $31-45$ & 305 & 19.2 \\
\hline & $46-59$ & 126 & 8.0 \\
\hline & $>60$ & 30 & 1.9 \\
\hline & Not recorded & 1 & 0.06 \\
\hline \multirow[t]{5}{*}{ NBSZ branch } & Harare & 685 & 43.2 \\
\hline & Bulawayo & 293 & 18.5 \\
\hline & Gweru & 222 & 14.0 \\
\hline & Masvingo & 201 & 13.6 \\
\hline & Mutare & 185 & 12.7 \\
\hline \multirow[t]{3}{*}{ Marital status $(n=1071)$} & Married & 284 & 17.9 \\
\hline & Not married & 787 & 49.6 \\
\hline & Not recorded & 515 & 32.5 \\
\hline \multirow[t]{4}{*}{ Occupation $(\mathrm{n}=1091)$} & Students & 783 & 49.4 \\
\hline & Professionals & 245 & 15.4 \\
\hline & Others & 63 & 4.0 \\
\hline & Not recorded & 495 & 31.2 \\
\hline \multirow[t]{2}{*}{ Donor Status } & First time & 232 & 14.6 \\
\hline & Repeat & 1354 & 85.4 \\
\hline
\end{tabular}

NBSZ-National Blood Service Zimbabwe.

Table 2. Prevalence of transfusion transmissible infections among blood donors in five blood service branches, Zimbabwe, $2018(\mathrm{~N}=1586)$.

\begin{tabular}{ccc}
\hline TTI & Number of reactive & Percentage with 95\% CI \\
\hline All TTI & 13 & $0.81(0.44-1.39)$ \\
HIV & 5 & $0.32(0.10-0.73)$ \\
HBV & 7 & $0.44(0.17-0.91)$ \\
Syphilis & 1 & $0.06(0.002-0.35)$ \\
HCV & 0 & - \\
Co-infection & 0 & - \\
\hline $\begin{array}{l}\text { TTI-transfusion transmissible infections, HIV-human immunodeficiency virus, HBV-hepatitis B virus, } \\
\text { HCV-hepatitis C virus. }\end{array}$ &
\end{tabular}


Table 3. Factors associated with transfusion transmissible infections among blood donors in five blood service branches, Zimbabwe, $2018(\mathrm{~N}=1586)$.

\begin{tabular}{|c|c|c|c|c|}
\hline & Characteristics & Total & Any TTI & P-value \\
\hline & Total & 1586 & $13(0.81)$ & \\
\hline \multirow[t]{2}{*}{ Gender } & Male & 972 & $9(0.93)$ & 0.555 \\
\hline & Female & 614 & $4(0.65)$ & \\
\hline \multirow[t]{4}{*}{ Age groups in years $(n=1585)$} & $16-30$ & 1124 & $6(0.53)$ & 0.014 \\
\hline & $31-45$ & 305 & $7(2.30)$ & \\
\hline & $46-59$ & 126 & 0 & \\
\hline & $>60$ & 30 & 0 & \\
\hline \multirow[t]{5}{*}{ NBSZ branch } & Harare & 685 & $5(0.73)$ & 0.524 \\
\hline & Bulawayo & 293 & $2(0.68)$ & \\
\hline & Gweru & 222 & $4(1.80)$ & \\
\hline & Masvingo & 201 & $1(0.54)$ & \\
\hline & Mutare & 185 & $1(0.50)$ & \\
\hline \multirow[t]{3}{*}{ Marital Status. } & Married & 284 & $5(1.80)$ & 0.132 \\
\hline & Not married & 787 & $4(0.51)$ & \\
\hline & Not recorded & 515 & $4(0.78)$ & \\
\hline \multirow[t]{4}{*}{ Occupation } & Students & 783 & $3(0.38)$ & 0.212 \\
\hline & Professionals & 245 & $4(1.63)$ & \\
\hline & Others & 63 & $1(1.59)$ & \\
\hline & Not recorded & 495 & $5(1.01)$ & \\
\hline \multirow[t]{2}{*}{ Donor Status } & First time & 232 & $11(4.74)$ & $<0.001$ \\
\hline & Repeat & 1354 & $2(0.15)$ & \\
\hline
\end{tabular}

NBSZ: National Blood Service Zimbabwe, TTI-transfusion transmissible infections.

\section{Discussion}

In our study, the overall prevalence of TTI was low, with the HBV prevalence being the highest followed by HIV prevalence. The findings were consistent with previous studies [9]. There has been a steady decrease in the overall prevalence of TTI from $\sim 4 \%$ in 2010 to $<1 \%$ in the present study and this decrease has been recorded for all the TTI in Zimbabwe [9]. Similar declining trends in prevalence have been reported in sub-Saharan Africa [10].

There was a male dominated blood donor pool (61.3\%) in this study. A similar demographic pattern for males has also been reported in studies from other parts of the world such as; India (95.2\%, Pakistan (99.6\%), Cameroon (82.0\%), Ethiopia (86.8\%) and Mexico (81.9\%) [2] [5]. This observation could be attributed to the cultural dogma that women should abstain from blood donation as they do lose blood monthly via menstruation.

The worldwide decline in the universal TTI prevalence is a result of improved 
control of sexually transmitted infections, introduction of mandatory screening for TTI and launching of intervention programs such as; regularly educating blood donors to lead a less risk lifestyle and recognising blood donors who achieve outstanding blood donation milestones [11] [12]. Furthermore, the specific decline in Zimbabwe can also be attributed to improved donor screening through the internally improved blood donor risk and inventory model. However, continued commitment and funding are required to further reduce the prevalence.

The TTI prevalence among first-time donors was $\sim 5 \%$ compared to the prevalence of $0.15 \%$ among repeat donors. This illustrated that repeat blood donors were the safer source of blood in Zimbabwe during the study period. A study in Zambia also confirmed similar findings [1]. Though the donor screening has improved still some blood units are discarded posing a cost and safety implication. Stricter mechanisms of donor screening are required. In addition, strategies to reduce the prevalence of HIV, HBV, and syphilis in the general population will also reduce the TTI prevalence in first-time donors.

In our study, only $15 \%$ were first-time donors, this is lower than what has been reported in most African countries [12]. This calls for recruitment strategies to increase the first-time donors and eventually, the entire pool. The results reflected a well-performing blood donor program which relies on retaining repeat donors.

We did not find HCV and co-infections among donors. Though this was encouraging, it could be due to two key reasons; first, the small study sample size, second; HCV transmission is most frequent in high-risk populations including people who inject drugs and men who have sex with men. These population groups are low in Zimbabwe [13].

The strengths of the study were that it used routinely available data which was kept in a central electronic database and the sample was fairly representative of a nation-wide donor population. Additional studies on this area can be further routinely be undertaken by NBSZ to obtain updated trends in the TTI prevalence and identify emerging risk factors.

\section{Conclusion}

This study has shown a low TTI prevalence in Zimbabwe with an evident higher prevalence of HBV. Blood safety is being maintained in Zimbabwe. We recommend continued close monitoring of the most risk sub-populations, and adoption of new TTI testing technologies.

\section{Limitation}

The study could not assess the odds ratios and/or risk ratios as we did not have a sufficient number of persons with TTIs. Information on occupation and marital status was missing in one third of the records.

\section{Acknowledgements}

This research was conducted through the Structured Operational Research and 
Training Initiative (SORT IT), a global partnership led by the Special Programme for Research and Training in Tropical Diseases at the World Health Organization (WHO/TDR). The training model is based on a course developed jointly by the International Union Against Tuberculosis and Lung Disease (The Union) and Medécins sans Frontières (MSF). The specific SORT IT program which resulted in this publication was implemented by the Centre for Operational Research, The Union, Paris, France. Mentorship and the coordination/facilitation of this particular SORT IT workshop was provided through the Centre for Operational Research, The Union, Paris, France; the Department of Tuberculosis and HIV, The Union, Paris, France; The Union, Zimbabwe Office; The Union, South East Asia Office; and AIDS \& TB Department, Ministry of Health \& Child Care, Harare, Zimbabwe. We also acknowledge the National Blood Service Zimbabwe (NBSZ) for providing support for the project to be successful.

\section{Funding and Resources}

The training course under which this study was conducted was funded by: The United Kingdom's Department for International Development (DFID); and the World Health Organization Zimbabwe Country Office. The open access publications costs were funded by the Department for International Development (DFID), UK and La Foundation Veuve Emile Metz-Tesch (Luxembourg). The funders had no role in authors' decisions. Study design, data collection and analysis, decision to publish, or preparation of the manuscript.

\section{Authors Contribution}

All the authors have made a significant contribution and have approved the publication of this paper.

\section{Conflicts of Interest}

The authors declare no conflicts of interest regarding the publication of this paper.

\section{References}

[1] Chama, D. (2015) THE University of Zambia Transfusion Transmissible Infections among Voluntary Blood Donors at the Lusaka Blood Transfusion Centre, 1-5.

[2] World Health Organization (2013) Voluntary Non-Remunerated Blood Donation, Geneva WHO.

[3] World Health Organization (2016) Global Status Report on Blood Safety, Geneva, WHO.

[4] National Blood Service Zimbabwe Report (2018) National Blood Service Zimbabawe, 1-64.

[5] Okoroiwu, H.U., Okafor, I.M., Asemota, E.A. and Okpokam, D.C. (2018) Seroprevalence of Transfusion-Transmissible Infections (HBV, HCV, Syphilis and HIV) among Prospective Blood Donors in a Tertiary Health Care Facility in Calabar, Ni- 
geria, an Eleven Years Evaluation. BMC Public Health, 18, Article No. 645. https://doi.org/10.1186/s12889-018-5555-X

[6] World Health Organization (2018) High Hepatitis B Prevalence among Zimbabwe Adults, Geneva, WHO.

[7] Charan, J. and Biswas, T. (2013) How to Calculate Sample Size for Different Study Designs in Medical Research? Indian Journal of Psychological Medicine, 35, 121-126. https://doi.org/10.4103/0253-7176.116232

[8] Jung, S. (2014) Stratified Fisher's Exact Test and Its Sample Size Calculation. BIMJ, 56, 129-140. https://doi.org/10.1002/bimj.201300048

[9] Mapako, T., Mvere, D.A., Chitiyo, M.E., et al. (2013) Human Immunodeficiency Virus Prevalence, Incidence, and Residual Transmission Risk in First-Time and Repeat Blood Donations in Zimbabwe, Implications on Blood Safety. Transfusion, 53, 2413-2421. https://doi.org/10.1111/trf.12311

[10] Mohammed, S. and Essel, H.B. (2018) Motivational Factors for Blood Donation, Potential Barriers, and Knowledge about Blood Donation in First-Time and Repeat Blood Donors. BMC Hematology, 18, Article No. 36.

https://doi.org/10.1186/s12878-018-0130-3

[11] O’Brien, S.F., Yi, Q.L., Fan. W., Scalia, V., Kleinman, S.H. and Vamvakas, E.C. (2007) Current Incidence and Estimated Residual Risk of Transfusion-Transmissible Infections in Donations Made to Canadian Blood Services. Transfusion, 47, 316-325. https://doi.org/10.1111/j.1537-2995.2007.01108.x

[12] National Agency for the Control of Aids (NACA) (2018) HIV Counseling and Testing. https://naca.gov.ng/hct-hiv-counseling-and-testing/

[13] Spearman, C.W., Dusheiko, G.M., Hellard, M. and Sonderup, M. (2029) Hepatitis C. The Lancet, 394, 1451-1466. https://doi.org/10.1016/S0140-6736(19)32320-7 